\title{
Adubação potássica na produção e qualidade pós-colheita de goiaba 'Paluma' no semiárido potiguar
}

\author{
Renato Dantas Alencar', Grazianny Andrade Leite ${ }^{2}$, Vander Mendonça ${ }^{3}$ \\ Franciezer Vicente de Lima ${ }^{3 *}$, Gustavo Alves Pereira ${ }^{3}$, Wagner Cesar de Farias ${ }^{3}$ \\ 'Instituto Federal de Educação, Ciência e Tecnologia do Rio Grande do Norte, Apodi, RN, Brasil \\ ${ }^{2}$ Universidade Federal Rural de Pernambuco, Cabo de Santo Agostinho, PE, Brasil \\ ${ }^{3}$ Universidade Federal Rural do Semi-Árido, Mossoró, RN, Brasil \\ Autor correspondente, e-mail: franciezer@hotmail.com
}

\section{Resumo}

O objetivo deste estudo foi avaliar o efeito da adubação potássica na produção e na qualidade final de frutos de goiabeiras 'Paluma', cultivadas no Distrito Irrigado do Baixo AçU-RN. O delineamento experimental empregado foi de blocos ao acaso, em parcela subdividida com cinco tratamentos $\left(0 ; 0,5 ; 1,0 ; 1,5\right.$ e $2,0 \mathrm{~kg} \mathrm{~K}_{2} \mathrm{O}$ planta $\left.^{-1}\right)$ e quatro repetições. As subparcelas foram compostas por duas épocas de colheita. Foram avaliadas as seguintes características: número de frutos comerciáveis, produção comercial, produção total, produtividade comercial, peso médio de frutos comerciáveis e peso médio de frutos totais. Na qualidade dos frutos foram avaliadas: vitamina c, sólidos solúveis, firmeza, acidez titulável, potencial hidrogeniônico da polpa, comprimento e diâmetro do fruto. Constatou-se que o aumento da dose de $\mathrm{K}_{2} \mathrm{O}$ promoveu um aumento linear no número de frutos, com a maior produtividade obtida na dose de $0,370 \mathrm{~kg}$ de $\mathrm{K}_{2} \mathrm{O}$ por planta, e maior firmeza dos frutos com a dose de $1,2 \mathrm{~kg}$ de $\mathrm{K}_{2} \mathrm{O}$ por planta.

Palavras-Chave: fruticultura, nutrição de plantas, Psidium guajava L.

\section{Potassium fertilization influencing the production and postharvest quality of 'Paluma' guava grown under semiarid conditions at Rio Grande do Norte, Brazil}

\begin{abstract}
The aim of this study was to evaluate the effect of potassium fertilization on yield and final quality of guava fruit variety 'Paluma', grown at the Irrigated District of Baixo AçU-RN, Brazil. The experimental was carried out in a completelyrandomized blocks design in split plot with five treatments $(0,0.5,1.0$, 1.5 and $2.0 \mathrm{~kg} \mathrm{~K}_{2} \mathrm{O}$ plant $^{-1}$ ) with four repetitions. The subplots were composed of two harvest seasons and the following characteristics were evaluated: number of fruits, commercial production, total production, commercial yield, average weight of commercial fruits and average weight of total fruit. For fruit quality the following characteristics were evaluated: vitamin $\mathrm{C}$, soluble solids content, firmness, titratable acidity, flesh $\mathrm{pH}$, fruit length and. With an increasie of $\mathrm{K}_{2} \mathrm{O}$ dose, a linear increase in the number of fruits was observed and ahigher yield was obtained when a dose of $0.370 \mathrm{~kg} \mathrm{~K}_{2} \mathrm{O}$ per plant was applied and a higher fruit firmness was obtained with a dose of $1.2 \mathrm{~kg} \mathrm{~K}{ }_{2} \mathrm{O}$ per plant.
\end{abstract}

Keywords: fruit growing, plant nutrition, Psidium guajava L. 


\section{Introdução}

A goiabeira (Psidium guajava L.) é originária da América Tropical, e cultivada em todas as regiões tropicais e subtropicais do mundo. No Brasil, é explorada em escala comercial em quase todas suas regiões, e amplamente cultivada em áreas irrigadas do semiárido nordestino, situando-se entre uma das fruteiras de maior valor econômico para região Nordeste brasileira (Cavalcante et al., 2010; Freitas \& Alves, 2008). Considerada a mais brasileira das frutas tropicais, sendo apreciada por seu aroma e sabor característicos, além do seu alto valor alimentício (Hernandes et al., 2012; Augostinho et al., 2008).

A cultivar Paluma apresenta entre suas características, dupla finalidade, consumo in natura e industrialização, sendo esse um dos fatores marcantes de sua exploração. Outro fator relevante é a capacidade para alcançar elevadas produtividades (Pereira \& Nachtigal, 2009).

Portanto, a correta nutrição das plantas é fundamental para que a absorção dos nutrientes seja realizada de forma equilibrada. Dessa forma, o estado nutricional das culturas pode afetar na composição final do fruto, na produtividade, no tamanho, na conservação pós-colheita e na resistência a pragas, dentre outros fatores (Aular \& Natale, 2013).

Plantas deficientes em potássio caracterizam-se por apresentar um crescimento lento, raízes pouco desenvolvidas, caules fracos e muito flexíveis e mais suscetíveis a ataques de doenças, além de prejudicar a formação de sementes e frutos com menor tamanho e consequentemente menor produção (Garcia et al., 2008).

A literatura apresenta variação de resultados sobre os efeitos da aplicação de fertilizantes na produção e na qualidade dos frutos (Maia et al., 2007; Dantas et al., 2007; Rozane et al., 2009). Mas, não para as condições edafoclimáticas da região estudada, visto a notada importância para os agricultores, e o elevado potencial produtivo da região, como também para o consumidor final na aquisição de frutos com melhor qualidade. Abre-se então, a necessidade da geração de maiores informações por meio de pesquisas sobre as dosagens com adubação potássica para essa cultura, uma vez que, plantas bem nutridas apresentam, dentre outros aspectos, maior capacidade de expressar seu máximo potencial produtivo (Santos et al., 2014).

Por isso, os efeitos da adubação sobre a qualidade final dos frutos devem ser cuidadosamente analisados, tornando-se necessário determinar as doses de nutrientes que resultem em máxima produção econômica e melhor qualidade de frutos nas condições climáticas estudadas. Desta forma, objetivou-se com este estudo avaliar o efeito da adubação potássica na produção e na qualidade final de frutos de goiabeiras da variedade 'Paluma', cultivadas no Distrito Irrigado do Baixo AçU-RN.

\section{Material e Métodos}

O experimento foi conduzido durante dois ciclos de cultivo do ano 2013, em um pomar no Distrito Irrigado do Baixo AçU (DIBA), localizado no Vale do Açu, município de Alto do Rodrigues, RN.

Segundo a classificação climática de Köppen, o clima da região é do tipo BSwh', ou seja, quente e seco, tipo estepe, com estação chuvosa no verão atrasando-se para o outono, com precipitação anual de 450 a 600 mm, distribuídas entre os meses de fevereiro a maio (Carmo Filho et al., 1987).

A área experimental foi composta por um pomar com três anos de idade, formado por goiabeiras da cultivar 'Paluma', propagadas por estaquia e cultivadas em espaçamento de $6 \times 5 \mathrm{~m}$, em solo do tipo VERTISSOLO Eutrófico e irrigadas por microaspersão, sendo a água fornecida de acordo com a evapotranspiração potencial de referência (ETo) média dos últimos cinco dias, utilizando-se o coeficiente da cultura (Kc de 0,60) conforme a equação de PenmamMonteith. Antes da aplicação dos tratamentos as plantas receberam poda de frutificação e coroamento num raio de aproximadamente 50 cm para fora da projeção da copa.

Após a realização da poda, coletaramse amostras de solo de forma aleatória na área, para análise da fertilidade, nas profundidades de $0-20$ e de $20-40 \mathrm{~cm}$. Após a coleta, o solo 
foi seco ao ar, moído e tamisado em peneira com malha de $2 \mathrm{~mm}$, e encaminhado para o Laboratório de Análise de Solo, Planta, água e Solo (LASAP) da Universidade Federal Rural do Semiárido (UFERSA), onde foram realizadas as análises, cujos resultados encontram-se na Tabela 1.

Tabela 1. Análise química do solo, tipo VERTISSOLO Eutrófico, nas camadas de 0-20 e de $20-40 \mathrm{~cm}$, do Distrito Irrigado do Baixo Açú (Alto do Rodrigues, RN, 2013) antes da instalação do experimento.

\begin{tabular}{|c|c|c|c|c|c|c|c|c|c|}
\hline \multirow{2}{*}{ Profundidade } & $\mathrm{pH}$ & $\mathrm{H}+\mathrm{Al}$ & $\mathrm{Al}$ & $\mathrm{Na}$ & $\mathrm{Ca}$ & $\mathrm{Mg}$ & K & $\mathrm{P}$ & \multirow{2}{*}{$\frac{M O}{(\%)}$} \\
\hline & Água & $\ldots \ldots \ldots \ldots$ & $\mathrm{ng} / \mathrm{dn}$ & $\ldots \ldots \ldots \ldots$ & \multicolumn{4}{|c|}{...............cmolc/dm ${ }^{3} \ldots \ldots \ldots \ldots \ldots$} & \\
\hline $0-20$ & 7,70 & 0,00 & 0,00 & 35,5 & 11,0 & 2,30 & 698,3 & 5,6 & 1,14 \\
\hline $20-40$ & 7,46 & 0,00 & 0,00 & 65,1 & 13,40 & 1,70 & 273,8 & 6,3 & 0,61 \\
\hline
\end{tabular}

O delineamento experimental utilizado foi em blocos casualizados, em parcelas subdivididas, sendo utilizadas quatro repetições. A parcela principal foi composta pelas doses de potássio $\left(0 ; 0,5 ; 1,0 ; 1,5\right.$ e 2,0 kg planta $\left.^{-1}\right)$ e as subparcelas por duas épocas consecutivas de produção. Cada parcela experimental foi composta por cinco plantas, sendo utilizadas como área útil, as três plantas centrais. As parcelas foram isoladas uma das outras, através de uma linha de plantio paralela nos dois lados da mesma. A fonte de potássio utilizada foi o cloreto de potássio ( $58 \%$ de $\mathrm{K}_{2} \mathrm{O}$ ), que foi parcelada em três aplicações a cada 30 dias, o fertilizante foi distribuído aproximadamente a $50 \mathrm{~cm}$ do caule da planta e na projeção de sua copa.

No final de cada ciclo, foram avaliadas as seguintes características: número de frutos comerciáveis (NFC), produção comercial (PC), produção total (PT), produtividade comercial (PdeC), peso médio de frutos comerciáveis (PMFC) e peso médio de frutos totais (PMFT).

Também foram procedidas análises póscolheita dos frutos, realizadas no Laboratório de Agricultura Irrigada da UFERSA, com frutos em estádio de maturação 4 e 5, utilizando-se 12 frutos por unidade experimental. Avaliaram-se as variáveis: Vitamina C (Vit.C), Sólidos solúveis (SS), Firmeza (Firm), acidez titulável (AT), potencial hidrogeniônico $(\mathrm{pH})$ da polpa; comprimento do fruto (CF) e diâmetro do fruto (DF), seguindo a metodologia de AOAC (1992).

Os dados obtidos foram submetidos à análise de variância, as médias dos dados quantitativos foram submetidas à análise de regressão, ajustando-se a um modelo com significância de no mínimo $5 \% \quad(p<0,05)$. Para dados qualitativos, utilizou-se o teste Tukey $(p<0,05)$. As análises de variância e de regressão foram realizadas pelo SISVAR (Ferreira, 2011).

\section{Resultados e Discussão}

O aumento das doses de potássio na produção de frutos de goiabeira 'Paluma' promoveu um efeito significativo $1 \%(p<0,01)$ pelo teste $F$, para as variáveis, número de frutos comerciais (NFC), produção comercial (PC) e produtividade comercial (PdeC). Em relação à interação entre as doses de potássio utilizadas e as épocas de cultivo, houve um efeito significativo em nível de $5 \%(p<0,05)$, para 0 peso comercial (PC) e produtividade comercial (PdeC), enquanto que para a produção total (PT) foi verificada uma significância em nível de $1 \%(p<0,01)$ (Tabela 2).

Referindo-se às épocas de colheita, todas as variáveis analisadas apresentaram efeito significativo ao nível de $1 \%(p<0,01)$ de probabilidade, o que pode ser explicado pelo excesso de precipitação (aproximadamente $1100 \mathrm{~mm}$ ) que ocorreu na segunda época de colheita, produzindo alagamento do pomar e a alta incidência de fungos, resultando, com isso, em uma baixa produção e consequentemente grandes diferenças entre as duas épocas avaliadas.

Com relação ao número de frutos comercializáveis (NFC), verificou-se um comportamento linear crescente em resposta ao aumento das doses de potássio (Figura 1a), estes resultados concordam com os encontrados por Natale et al., (1996). Quando se refere às épocas de colheita (Figura 1b), constatou-se uma redução da ordem de $85 \%$ na quantidade de frutos colhidos por planta, entre a primeira e a 
segunda safra, estação de estiagem e estação de elevada precipitação, respectivamente, que culminou com o alagamento do pomar por algumas semanas.

Tabela 2. Resumo da análise de variância para as variáveis de produção de frutos de goiabeira 'Paluma' em função de doses potássio $\left(\mathrm{K}_{2} \mathrm{O}\right)$ e de diferentes épocas de produção (E).

\begin{tabular}{|c|c|c|c|c|c|c|c|}
\hline \multirow[t]{2}{*}{ FV } & \multirow[t]{2}{*}{ GL } & \multicolumn{6}{|c|}{ Quadrado médio } \\
\hline & & NFC & PC & PT & PdeC & PMFC & PMFT \\
\hline K & 4 & $3706,5^{* *}$ & $22,28^{* *}$ & $67,25^{* *}$ & $2,48^{* *}$ & $898,29^{\text {ns }}$ & $909,59^{\text {ns }}$ \\
\hline Errol & 12 & 522,9 & 3,69 & 9,56 & 0,41 & 359,29 & 312,76 \\
\hline$E$ & 1 & $86623,5^{* *}$ & $4114,5^{* *}$ & $17704,9^{* *}$ & $457,17^{* *}$ & $2455,72^{* *}$ & $6699,43^{* *}$ \\
\hline $\mathrm{KXE}$ & 4 & $2018,9^{\mathrm{ns}}$ & $21,44^{*}$ & $70,04^{* *}$ & $2,38^{*}$ & $617,79^{\text {ns }}$ & $612,75^{\text {ns }}$ \\
\hline Erro2 & 15 & 1040,1 & 6,23 & 13,65 & 0,69 & 427,84 & 343,90 \\
\hline CV1(\%) & - & 11,00 & 10,75 & 10,66 & 10,74 & 18,22 & 15,57 \\
\hline CV2(\%) & - & 15,51 & 13,97 & 12,74 & 13,97 & 19,88 & 16,32 \\
\hline Média & - & 207,95 & 17,87 & 29,01 & 5,96 & 104,06 & 113,61 \\
\hline
\end{tabular}

A.

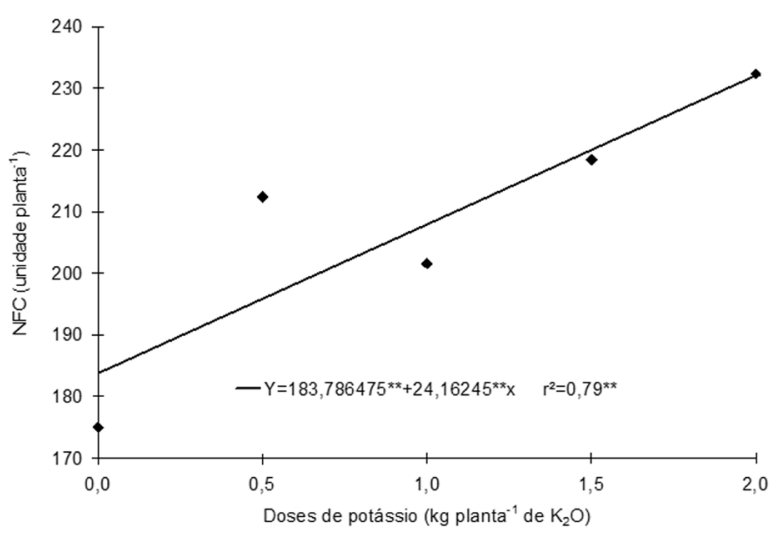

B.

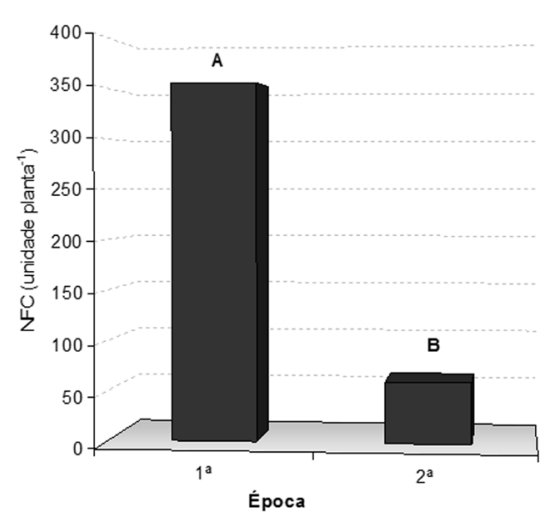

Figura 1. Número de frutos comerciáveis em função da adubação potássica (a) e número de frutos comerciáveis em função de diferentes épocas de produção (b) de frutos de goiabeira 'Paluma'.

Estes resultados corroboram com os verificados por Lima et al., (2008) que constataram aumento linear do número de frutos, utilizando doses crescentes de $\mathrm{K}_{2} \mathrm{O} \mathrm{ha-1}$. Porém, Natale et al., (1996), trabalhando com goiabas variedade Paluma, constataram que 90\% da produção máxima da goiabeira estaria associada à dose de $635 \mathrm{~g} \mathrm{~K}_{2} \mathrm{O}$ planta ${ }^{-1}$.

No que se refere a variável produção de frutos comercializáveis por planta (figura $2 a)$, verificou-se efeito significativo $(p<0,01) \mathrm{com}$ comportamento quadrático na primeira safra, enquanto que na estação chuvosa não se verificou efeito significativo, quando o peso dos frutos comercializáveis estimado foi de $29,6 \mathrm{~kg}$ planta $^{-1}$ com a dose de 1,5 kg de $\mathrm{K}_{2} \mathrm{O}$ planta $^{-1}$.

A partir da dose de 1,5 kg planta ${ }^{-1}$, o peso de frutos comercializáveis apresentou tendência de redução. Lima et al. (2008) utilizando doses que variaram de 100 a $400 \mathrm{~g}_{\text {planta }}{ }^{-1}$ de potássio obtiveram comportamento crescente linear para a produção de frutos de goiaba.

Em relação à primeira e à segunda safra de colheita (figura 2b), observa-se que o peso comercial de frutos por planta (PC) apresentou redução na ordem de $74,2 \%$ da primeira para a segunda colheita, que é atribuída ao excesso de umidade (alagamento) durante a frutificação e a colheita, que provocou abortamento de frutos, ataque de fungos às plantas e aos frutos, ocasionando queda na produção. Souza et al. (2010) relata as implicações proporcionadas pelo excesso de umidade do solo no desenvolvimento e produção da cultura da goiabeira.

Quanto à produção total por planta (Figura 3a), verificou-se efeito significativo 
$(p<0,01)$ na primeira safra (estiagem) com a produção máxima de $55,7 \mathrm{~kg}$ na dose de 0,330 $\mathrm{kg}$ de $\mathrm{K}_{2} \mathrm{O}$ planta $^{-1}$, valor pouco superior ao verificado por Natale et al. (1996) que obtiveram a maior produção com a dose de $0,290 \mathrm{~kg}$ de $\mathrm{K}_{2} \mathrm{O}$ planta-1 para a cultivar Paluma. Lima et al. (2008) obtiveram produção crescente em goiabeiras, utilizando doses de $\mathrm{K}_{2} \mathrm{O}$ de 100 a $400 \mathrm{~g}_{\text {plantas }}{ }^{-1}$, com a produção total de aproximadamente 25 $\mathrm{kg}$ planta $^{-1}$ na dose $400 \mathrm{~g} \mathrm{planta}^{-1}$.

Já entre as épocas de produção (Figura 3b), constatou-se uma redução da ordem de $84 \%$ na produção total de frutos por planta (PT), atribuída ao alagamento do pomar.
A.

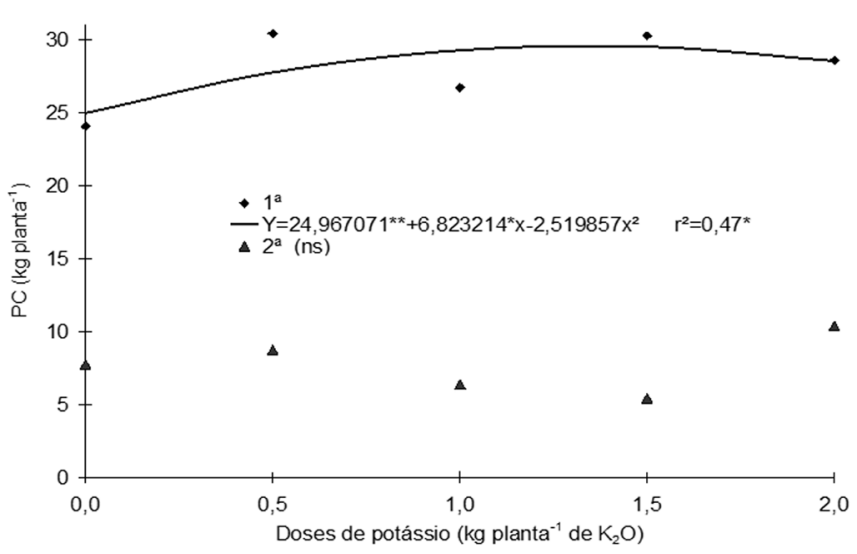

B.

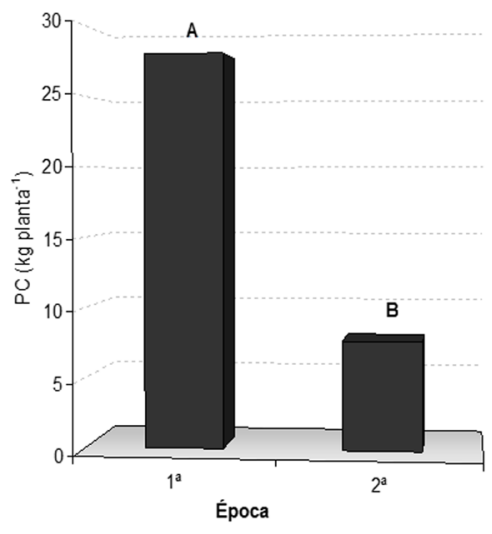

Figura 2. Produção comercial de frutos por planta em função da adubação potássica (a) e produção comercial de frutos por planta em função de diferentes épocas de produção (b) de frutos de goiabeira 'Paluma'.

A.

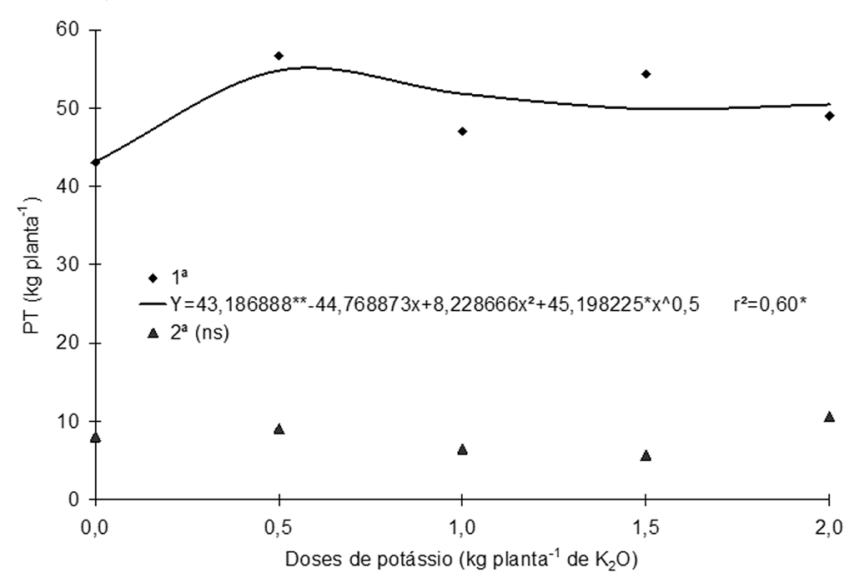

B.

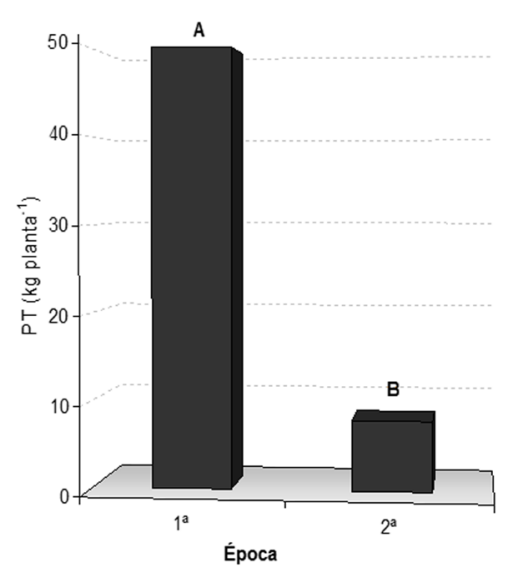

Figura 3. Produção total em função da adubação potássica (a) e Produção total em função de diferentes épocas de produção (b) de frutos de goiabeira 'Paluma'.

A produtividade comercial máxima estimada foi de 9,91 ton ha-1 (Figura 4a), com a dose de $0,370 \mathrm{~kg}$ de $\mathrm{K}_{2} \mathrm{O}$ planta-1 $^{-1}$, valor superior ao verificado por Natale et al. (1996) que obtiveram a maior produtividade com a dose de $0,290 \mathrm{~kg}$ de $\mathrm{K}_{2} \mathrm{O}$ planta $^{-1}$. Em relação às épocas (Figura $4 \mathrm{~b}$ ), também se observa o mesmo comportamento encontrado nas variáveis anteriores.

Um dos fatores conhecidos na cultura da goiabeira, em relação às exigências do nutriente potássio, é que o mesmo é mais consumido e exportado por goiabeiras em fase produção, trazendo forte influencia nas características finais do fruto (Souza et al., 2013; Souza et al., 2012), a deficiência de potássio ocasiona - funcionamento irregular dos estômatos, podendo diminuir a assimilação de $\mathrm{CO}_{2}$, e a taxa fotossintética, afetando negativamente a produção (Feitosa et al., 2013).

Neste trabalho, a adubação potássica 
não promoveu efeito significativo $(p>0,05)$ pelo teste $F$, para a variável vitamina $C$, sólidos solúveis, acidez titulável, comprimento do fruto e diâmetro do fruto, tendo como valores médios: $80,72 \%, 8,53{ }^{\circ}$ Brix, $6,34 \%, 6,54 \mathrm{~cm}$ e $6,70 \mathrm{~cm}$, respectivamente. Para a firmeza da polpa e o potencial hidrogeniônico, foi verificado um efeito significativo em nível de $5 \%(p<0,05)$ de significância para o aumento da adubação potássica (Tabela 3).
A.

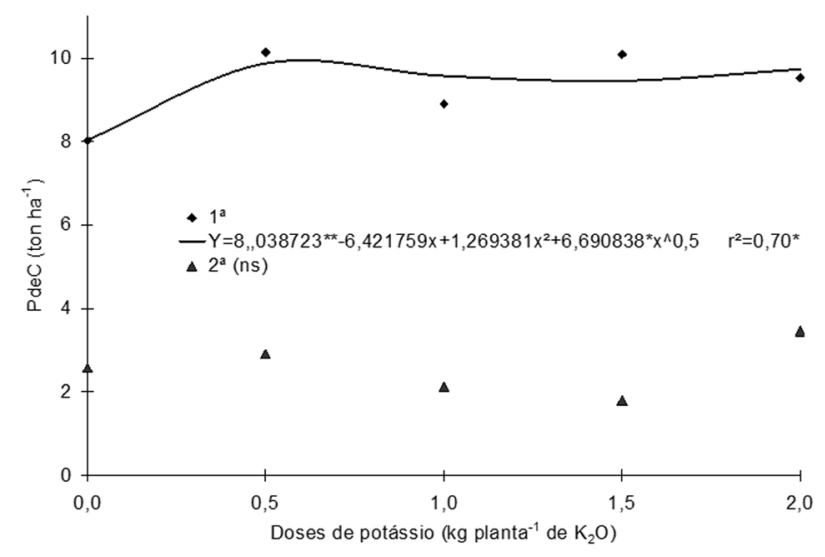

B.

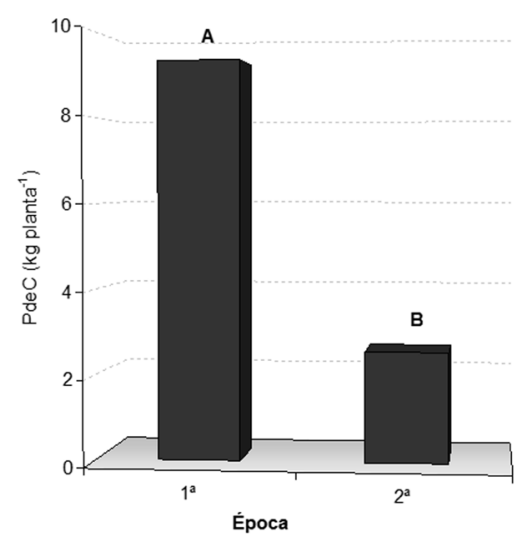

Figura 4. Produtividade comercial em função da adubação potássica (a) e Produtividade comercial em função de diferentes épocas de produção (b) de frutos de goiabeira 'Paluma'.

Tabela 3. Resumo da análise de variância para as variáveis de qualidade pós-colheita de frutos de goiabeira 'Paluma' em função de doses de potássio (K) e de diferentes épocas de produção (E).

\begin{tabular}{|c|c|c|c|c|c|c|c|c|}
\hline \multirow{2}{*}{$\mathrm{FV}$} & \multirow{2}{*}{ GL } & \multicolumn{7}{|c|}{ Quadrado médio } \\
\hline & & Vit. C & SS & FIR & $\mathrm{AT}$ & $\mathrm{pH}$ & $\mathrm{CF}$ & DF \\
\hline$K$ & 4 & $113,98^{\text {ns }}$ & $0,28^{\text {ns }}$ & $28,59 *$ & $0,32^{\text {ns }}$ & $0,015^{*}$ & $0,12^{\text {ns }}$ & $4,39^{\text {ns }}$ \\
\hline Bloco & 3 & $43,11^{\mathrm{ns}}$ & $0,35^{\text {ns }}$ & $7,00^{\mathrm{ns}}$ & $1,99^{\mathrm{ns}}$ & $0,001^{\text {ns }}$ & $0,48^{\text {ns }}$ & 4,29 ns \\
\hline Erro 1 & 12 & 100,50 & 0,54 & 6,44 & 0,12 & 0,003 & 0,14 & 3,63 \\
\hline$E$ & 1 & $1226,86^{*}$ & $17,25^{* *}$ & $797,47^{* *}$ & $9,26^{* *}$ & $0,023^{\text {ns }}$ & $0,05^{\text {ns }}$ & $0,82^{\text {ns }}$ \\
\hline$K \times E$ & 4 & $70,87^{\mathrm{ns}}$ & $0,82^{\mathrm{ns}}$ & $13,02^{\text {ns }}$ & $0,29^{\text {ns }}$ & $0,021^{\mathrm{ns}}$ & $0,02^{\text {ns }}$ & $0,09^{\text {ns }}$ \\
\hline Erro 2 & 15 & 42,01 & 0,82 & 5,33 & 0,48 & $0,102^{\text {ns }}$ & $0,03^{\text {ns }}$ & 0,67 \\
\hline C.V. 1 (\%) & - & 12,42 & 8,53 & 13,88 & 5,57 & 1,43 & 5,74 & 28,44 \\
\hline C.V. $2(\%)$ & - & 8,03 & 10,50 & 12,63 & 10,90 & 2,75 & 8,47 & 35,84 \\
\hline Média & - & 80,72 & 8,61 & 18,28 & 6,34 & 3,87 & 6,54 & 6,70 \\
\hline
\end{tabular}

Ainda na Tabela 3, pode-se observar o efeito das épocas de produção de frutos da goiabeira, verificando-se o efeito significativo $(p<0,05)$ para a vitamina C. Já para as variáveis, sólidos solúveis, firmeza da polpa e acidez titulável da polpa, foi verificado efeito significativo $(p<0,01)$ pelo teste F. Para as demais variáveis estudadas não se constatou efeito da época de cultivo, assim como não houve interação entre a adubação potássica e as épocas de cultivo.

Possivelmente, a ausência de respostas para estas variáveis mesmo com o aumento das doses de potássio, pode ser devido aos altos índices de potássio presentes nas camadas 0-20 $\mathrm{cm}\left(698,3 \mathrm{cmol}_{\mathrm{c}} \mathrm{dm}^{-3}\right)$ e $20-40 \mathrm{~cm}\left(273,8 \mathrm{cmol}_{\mathrm{c}}\right.$ $\left.\mathrm{dm}^{-3}\right)$, conforme observado na Tabela 1 .

Com relação à firmeza do fruto, em resposta às doses de $\mathrm{K}_{2} \mathrm{O}$, os resultados se ajustaram ao modelo quadrático, sendo a máxima firmeza encontrada de 20 Newton $(\mathrm{N})$, obtida com a dose de 1,21 kg $\mathrm{K}_{2} \mathrm{O}$ planta $^{-1}$, verificando-se que após essa dosagem houve efeito depressivo quanto a essa variável (Figura 5a). Estes resultados foram semelhantes aos obtidos por Lima et al. (2008) que verificaram a firmeza de polpa de goiabas 'Paluma' nos estágios 4 e 5 de 18,7 e 15,5 N, respectivamente. Isto pode ser explicado devido ao potássio 
desempenhar importante papel na manutenção da turgescência celular, que contribui para a resistência do tecido (Lima et al., 2008; Souza et al., 2010), influenciando com isto na firmeza da polpa.

B.

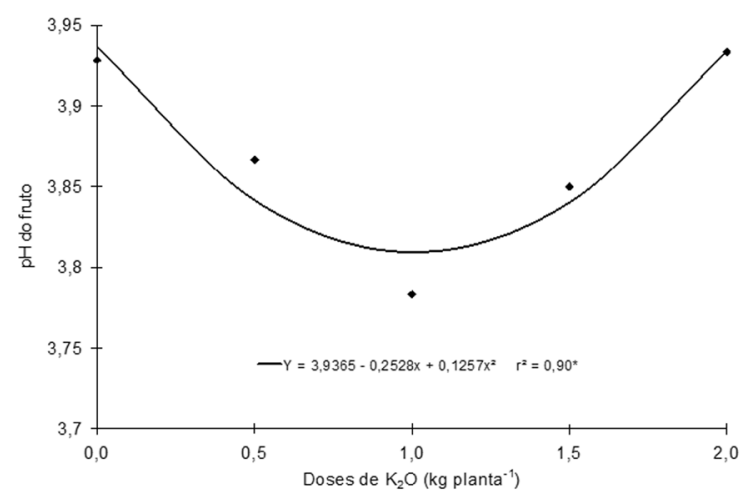

Figura 5. Firmeza (a) e Potencial hidrogeniônico (b) em frutos de goiabeira 'Paluma' em função da adubação potássica.

No que se refere ao $\mathrm{pH}$ da polpa, o comportamento côncavo da curva (Figura 5b), pode ser explicado pela desuniformidade do estádio de maturação dos frutos analisados, em que as amostras dos tratamentos T1 e T5 10 e 2,0 kg planta $^{-1}$ ) foram compostas por frutos em estádio de maturação 3 , enquanto que os demais tratamentos estavam no estádio 4 e 5 (mais avançados). Esta diferença na maturação dos tratamentos T2, T3 e T4 $(0,5 ; 1,0$ e 1,5 kg planta $^{-1}$ ) é resultante também da acidificação da polpa, ocasionando com isso uma redução no pH (Amarante et al., 2013).

Com relação às épocas de produção, a análise de variância das características de póscolheita estudadas, mostrou efeito altamente significativo $(p<0,01)$ para a variável vitamina C, sólidos solúveis, Brix e acidez titulável, possivelmente, estes resultados devem-se as diferenças nos estádios de maturação dos frutos que formavam as amostras dos tratamentos nas duas safras (épocas), como já relatado anteriormente.

A firmeza observada no primeiro e segundo ciclo (figura 6a) estão de acordo com as observadas por Lima et al. (2008), que obtiveram valores entre 18,7 e 15,5 N (Newton), respectivamente, para os estádios de maturação 4 e 5.

Como a segunda colheita foi bastante comprometida, amostras de frutos de alguns tratamentos tiveram que ser compostas por frutos em estádio de maturação 3, ou seja, que foram colhidos antes do estádio programado, o que resultou em características físico-químicas destoantes do estado ideal.

Com isso, os frutos que formavam as amostras do primeiro ciclo estavam em estádio de maturação mais avançado (4 e 5) quando comparados aos que formaram as amostras do segundo ciclo (maioria 3), o que resultou em uma menor firmeza de polpa do segundo ciclo (Figura 6a) devido a fatores como a maior solubilização da pectina na parede celular, a quebra do amido e a redução de turgor, essas características proporcionam uma redução do teor de proteínas resultando em aumento do conteúdo de água nos tecidos dos frutos mais maduros (Souza et al., 2010).

Com relação aos teores de vitamina C (Figura 6b), os valores observados no primeiro $\left(75,18 \mathrm{mg} 100 \mathrm{~g}^{-1}\right)$ e no segundo ciclo $(86,26 \mathrm{mg}$ $100 \mathrm{~g}^{-1}$ ) estão de acordo com os verificados por Lima et al. (2008) que obtiveram teores variando entre 49 a $86 \mathrm{mg} 100 \mathrm{~g}^{-1}$. Observou-se também efeito significativo $(p<0,01)$ para vitamina $C$, entre as épocas de colheita.

Quanto à acidez titulável (Figura 6c), os valores encontrados variaram entre 75, 18 e 86,26 $\%$, apresentando comportamento semelhante ao verificado com os teores de vitamina C.

A duração no período de maturação e a qualidade dos frutos da goiabeira necessitam ser relacionadas com as variáveis meteorológicas 
aos quais as plantas foram expostas, com o objetivo de se obterem implicações que melhor expliquem a variabilidade dos indicadores de qualidade durante uma safra (SERRANO et al., 2007). A redução do teor de sólidos solúveis, por exemplo, pode ocorrer pelo excesso de água na época do enchimento do fruto, enquanto a concentração de açúcares pode ser favorecida pela escassez de água (Souza et al., 2010).

Para os sólidos solúveis (Figura 6d), os valores encontrados variaram entre 7,95 e 9,26 Brix, e estão coerentes com a literatura. Contudo, são inferiores aos encontrados por Lima et al.
(2008) que ficaram na faixa 9,5 a $11^{\circ}$ Brix.

Souza et al. (2010) relatam a influência das precipitações pluviométricas nos atributos físico-químicos de frutos da goiabeira 'Paluma' em diferentes estádios de maturação. Isto pode ajudar a explicar a redução do ${ }^{\circ}$ Brix encontrado neste trabalho, uma vez que, por causa desta eventualidade, os frutos da segunda época de colheita tiveram de ser colhidos prematuramente, e estavam em sua maioria no estágio de maturação 3, enquanto que, as amostras do primeiro ciclo estavam em estádio 4 e 5 .
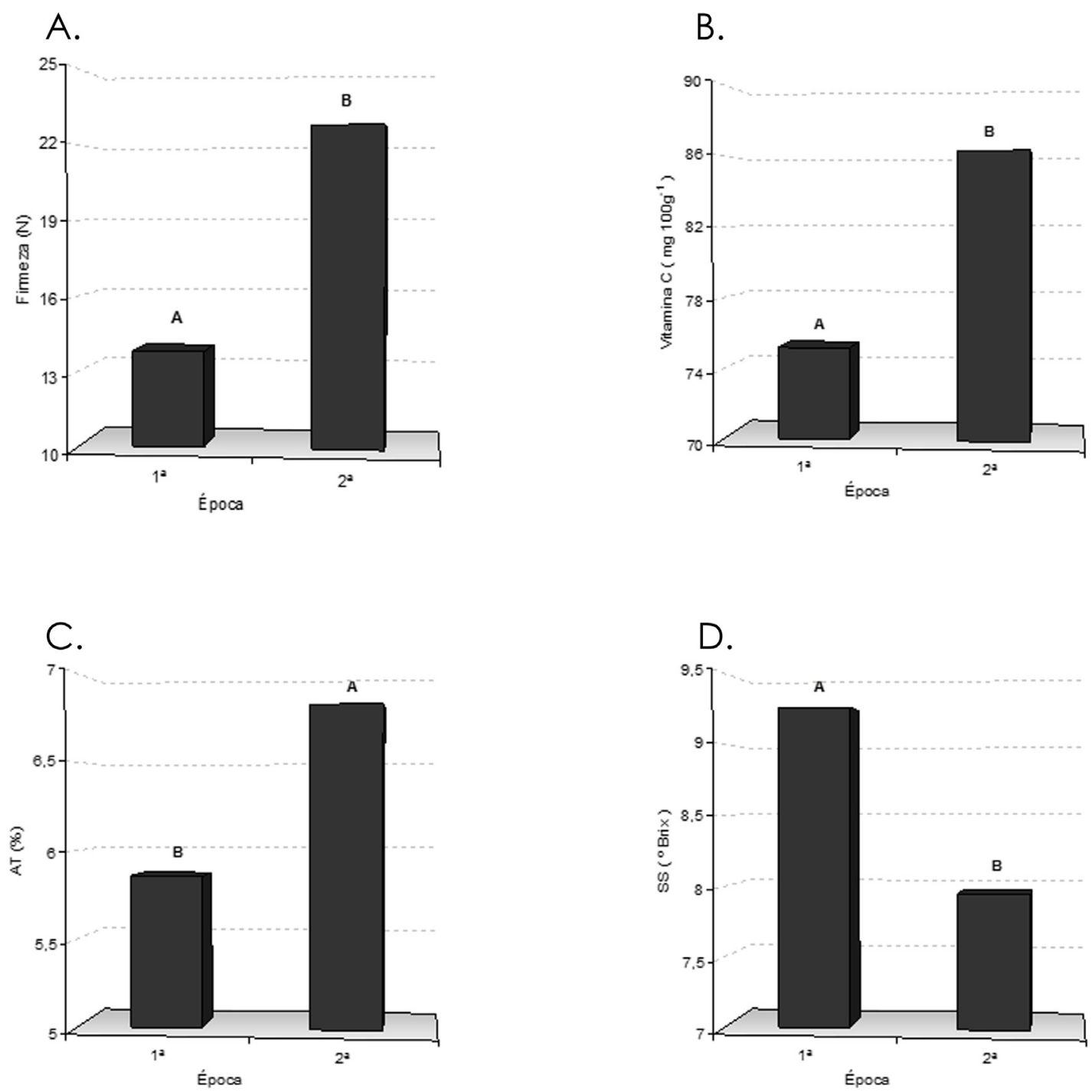

Figura 6. Firmeza (a), vitamina C (b), acidez titulável-AT (c) e sólidos solúveis-SS (d) de frutos de goiabeira 'Paluma' em diferentes épocas de produção 


\section{Conclusões}

Constatou-se que, com o aumento das doses de $\mathrm{K}_{2} \mathrm{O}$ foi verificado um aumento linear no número de frutos, com a maior produtividade obtida na dose de 0,370 kg de $\mathrm{K}_{2} \mathrm{O}$ por planta ${ }^{-1}$.

Os melhores valores para o peso dos frutos comercializáveis foi estimado com a dose de $1,5 \mathrm{~kg}$ de $\mathrm{K}_{2} \mathrm{O}$ planta $^{-1}$.

E a maior firmeza dos frutos com a dose de $1,2 \mathrm{~kg}$ de $\mathrm{K}_{2} \mathrm{O}$ por planta ${ }^{-1}$.

\section{Referências}

Amarante, C.V.T.D., Steffens, C.A., Benincá, T.D.T., Hackbarth, C., Santos, K.L.D. 2013. Qualidade e potencial de conservação Pós-colheita dos frutos em cultivares brasileiras de goiabeiraserrana. Revista Brasileira de Fruticultura 35: 990999.

AOAC. 1992. Official methods of analysis of the Association of the Agricultural Chemistis. AOAC Washington, USA. $1115 \mathrm{p}$.

Augostinho, L.M.D., Prado, R.D.M., Rozane, D.E. Freitas, N. 2008. Acúmulo de massa seca e marcha de absorção de nutrientes em mudas de goiabeira 'Pedro Sato'. Bragantia 67: 577-585.

Aular, J., Natale, W. 2013. Nutrição mineral e qualidade do fruto de algumas frutíferas tropicais: goiabeira, mangueira, bananeira e mamoeiro. Revista Brasileira de Fruticultura 35: 1214-1231.

Carmo Filho, F., Espínola Sobrinho, J., Amorim, A.P. 1987. Dados meteorológicos de Mossoró (janeiro de 1898 a dezembro de 1986). FGD, Mossoró, Brasil. 325 p.

Cavalcante, L.F., Vieira, M.D.S., Santos, A.F.D. Oliveira, W.M.D., Nascimento, J.A.M. D. 2010. Água salina e esterco bovino líquido na formação de mudas de goiabeira cultivar Paluma. Revista Brasileira de Fruticultura 32: 251-261.

Dantas, B.F., Pereira, M.S., Ribeiro, L.D.S., Maia, J.L.T., Silva, D.J., Duenhas, L.H., Lima, M.A.C.D., Bassoi, L.H. 2007. Metabolic responses of guava trees irrigated with different $\mathrm{N}$ and $\mathrm{K}$ levels in São Francisco Valley. Revista Brasileira de Fruticultura 29: 323-328.

Feitosa, H.D.O., Farias, G.C., Silva Junior, R.J.C., Ferreira, F.J., Andrade Filho, F.L., Lacerda, C.F. 2013. Influência da adubação borácica e potássica no desempenho do girassol. Comunicata Scientiae 4: 302-307.

Ferreira, D.F. 2011 . Sisvar: a computer statistical analysis system. Ciência e Agrotecnologia 35: 1039-1042.
Freitas, B.M., Alves, J.E. Efeito do número de visitas florais da abelha melífera (Apis mellifera L.) na polinização da goiabeira (Psidium guajava L.) cv. Paluma. 2008. Revista Ciência Agronômica 39: 148-154.

Garcia, O.J., Dueñez, E.Y., Fischer, G., Chaves, B., Quintero, O.C. 2008. Efecto del nitrato de potasio, fosfato de potasio y ethephon en la inducción floral de la feijoa o goiabeira serrana (Acca sellowiana [O. Berg] Burret). Revista Brasileira de Fruticultura 30: 577-584.

Hernandes, A., Parent, S.É., Natale, W., Parent, L.É. 2012. Balancing guava nutrition with liming and fertilization. Revista Brasileira de Fruticultura 34: 1224-1234.

Lima, M.A.C.de., Bassoi, L.H., Silva, D.J., Santos, P.S., Paes, P.C., Ribeiro, P.R.A., Dantas, B.F. 2008. Efeitos dos níveis de nitrogênio e potássio na produção e maturação de frutos de árvores irrigadas goiaba no Vale do São Francisco. Revista Brasileira de Fruticultura 30: 246-250.

Maia, J.L.T., Bassoi, L.H., Silva, D.J., Lima, M.A.C.D., Assis, J.S.D., Morais, P.L.D.D. 2007. Assessment on nutrient levels in the aerial biomass of irrigated guava in São Francisco Valley, Brazil. Revista Brasileira de Fruticultura 29: 705-709.

Natale, W., Coutinho, E.L.M., Boaretto, A.E., Pereira, F. M., Oioli, A.A., Sales, L. 1996. Nutrição e adubação potássica na cultura da goiabeira. Revista Brasileira de Ciência do Solo 20: 247-250.

Pereira, F.M., Nachtigal, J.C. 2009. Melhoramento genético da goiabeira. In: Natale, W., Rozane, D.E., Souza, H.A., Amorim, D.A. Cultura da goiaba: do plantio à comercialização. FCAV/ FAPESP, Jaboticabal, Brasil. p. 371-398.

Rozane, D.E., Prado, R.M., Barbosa, J.C., Natale, W. 2009. Tamanho da amostra foliar para avaliação do estado nutricional de goiabeiras com e sem irrigação. Revista Brasileira de Engenharia Agrícola e Ambiental 13: 233-239.

Santos, E.M., Cavalcante, Í.H.L., Silva Júnior, G.B., Albano, F.G., Lima, F.N., Sousa, A. M., Cavalcante, L.F. 2014. Estado nutricional do mamoeiro Formosa (cv. Caliman 01) em função de adubação com NK e espaçamento de plantio. Comunicata Scientiae 5: 229-240.

Serrano, L.A.L., Marinho, C.S., Ronchi, C.P., Lima, I.M., Martins, M.V.V., Tardin, F.D. 2007. Goiabeira 'Paluma' sob diferentes sistemas de cultivo, épocas e intensidades de poda de frutificação. Pesquisa Agropecuária Brasileira 42: 785-792.

Souza, H.A., Rozane, D.E., Romualdo, L.M., Natale, W. 2012. Efeitos de diferentes tipos de poda nos teores de nutrientes em flores e frutos de goiabeira. Idesia 30: 45-51. 
Souza, H.A.D., Rozane, D.E., Amorim, D.A.D., Natale, W. 2013. Normas preliminares dris e faixas de suficiência para goiabeira 'paluma'. Revista Brasileira de Fruticultura 35: 282-291.

Souza, M.E.de., Silva, A.C.da., Souza, A.P.de., Tanaka, A.A., Leonel, S. 2010. Influência das precipitações pluviométricas em atributos físico-químicos de frutos da goiabeira 'paluma' em diferentes estádios de maturação. Revista Brasileira de Fruticultura 32: 637-646. 